\title{
In adolescents with epilepsy, high scores of anxiety and depression are associated with occurrence of seizures in public places
}

\author{
Em adolescentes com epilepsia, altos escores de ansiedade e depressão foram \\ associados com ocorrência de crises em lugares públicos \\ Nathália F. Siqueira, Fernando L. B. B. Oliveira, Jorge A. Siqueira, Elisabete Abib Pedroso de Souza
}

\begin{abstract}
Objective: To assess depression and anxiety symptoms of adolescents with epilepsy compared with adolescents without epilepsy. Method: The study sample consisted of: case participants (50 subjects) attending the pediatric epilepsy clinic of a tertiary hospital and control participants (51 subjects) from public schools. The instruments utilized were: identification card with demographic and epilepsy data, Beck Depression Inventory and State-Trait Anxiety Inventory. Results: No significant differences were founded between the groups regarding scores for depression and anxiety symptoms but both groups presented moderate scores of anxiety. A correlation was found between low scores anxiety and not frequent seizures, low scores anxiety and perception of seizure control, high scores of anxiety and depression and occurrence of seizures in public places. Conclusion: Low scores of anxiety are associated with not frequent seizures; high scores of anxiety and depression are associated with occurrence of seizures in public places.
\end{abstract}

Keywords: epilepsy, adolescence, depression, anxiety, seizure frequency, perception of seizure control, occurrence of seizure in public places.

\section{RESUMO}

Objetivo: O presente estudo teve como objetivo avaliar os sintomas de ansiedade e depressão de adolescentes com epilepsia comparados com adolescentes sem epilepsia. Método: A amostra consistiu: grupo caso (50 indivíduos) atendidos no ambulatório de epilepsia infantil do Hospital Universitário e grupo controle (51 indivíduos) de escolas públicas. Os instrumentos utilizados foram: cartão com dados demográficos e de epilepsia, Beck Depression Inventory e State-Trait Anxiety Inventory. Resultados: Os resultados não mostraram diferenças significativas entre os grupos em relação à depressão e ansiedade, mas ambos os grupos apresentaram escores moderados de ansiedade. Foi encontrada correlação entre baixa pontuação de ansiedade e crises não frequentes e percepção de controle de crises; altas pontuações de ansiedade e depressão e ocorrência de crises em lugares públicos. Conclusão: Variáveis psicossociais e da doença são contingências importantes no comportamento adaptativo e controle do humor em uma doença crônica como a epilepsia.

Palavras-chave: epilepsia, adolescência, depressão, ansiedade, frequência de crises, percepção de controle de crises, ocorrência de crises em público.

Epilepsy has been recognized as a risk factor for negative outcomes in many aspects of the lives of people with this diagnosis, including emotional, psychological, academic, and social problems ${ }^{1}$. Prone to the social limitations that the diagnosis of epilepsy brings, many people with epilepsy suffer from moderate to severe depression and anxiety ${ }^{2}$.

Depression per se is one of the most commonly occurring major psychiatric disorders, and it has become increasingly recognized that the disease often begins in adolescence.
Depressive patients are often diagnosed with other illnesses, especially anxiety and disruptive behavioral disorders ${ }^{3}$.

In adults with epilepsy depression and anxiety are the most prevalent psychiatric disorders, affecting about $55 \%$ of subjects ${ }^{4}$. In children and adolescents, many studies were also carried out, developed with different designs and assessment tools, and presenting diverse outcomes.

Ettinger et al. ${ }^{5}$ applied the quantitative scales Revised Child Manifest Anxiety Scale (RCMAS) ${ }^{6}$ and Child Depression 
Inventory $(\mathrm{CDI})^{7}$ to assess depression and anxiety in a population of 44 children and adolescents (from 7 to 18 years) with epilepsy and found that $26 \%$ of patients had increased depression scores and $16 \%$ had anxiety symptomatology.

Dunn et al. ${ }^{8}$ studied adolescents with epilepsy aged 12-16 years in a cross-sectional design with 115 subjects and found that $23 \%$ of those had symptoms of depression (based on the CDI). Oguz et al. ${ }^{9}$ reported subjects aged $12-18$ years to have higher scores of depression (using the CDI) when compared with a control group with normal children, but both of the case groups (9-11 years and 12-18 years) showed increased anxiety based on the State Trait Anxiety Inventory (STAI) ${ }^{10}$, when compared with the control group.

Ott et al. ${ }^{11}$ investigated psychiatric illnesses in 114 children with epilepsy aged 5-16 years and found that $61 \%$ of the sample carried a psychiatric diagnosis, and, of those, only a third was receiving adequate mental health treatment. Caplan et al. ${ }^{12}$, with a similar sample (children with epilepsy aged 5-16 years) and tool approach, but with a comparison control group, observed increased rates of affective and anxiety disorders diagnoses ( $33 \%$ vs $6 \%$ - control) as well as suicidal ideation ( $20 \%$ vs $9 \%$ - control) for the case group.

More recently, Loney et al. ${ }^{13}$ assessed anxiety and depressive signs in children and adolescents from 7 to 17 years presenting at their clinic with a first seizure, using CDI and RCMAS. For anxiety, there was a higher score for case group versus published norms, but no difference when compared with the control group; for depression, scores were higher for case group when compared with both published norms and control group.

Depression and anxiety in children and adolescents with epilepsy requires further attention because it carries a risk of reduced quality of life and complications in life ${ }^{14}$. Although most studies agree that children and adolescents with epilepsy have a high level of depression and anxiety, it is possible to perceive differences among the numbers presented in these studies. Some of the reasons for the variability in prevalence may include an inadequate consideration of both biological and psychosocial factors ${ }^{15}$. These factors, including the developmental stages of a person, may be related to the subject age. The studies previously cited evaluated different age intervals, defined not by preexisting formal criteria for the age range for children and age range for adolescents, and their possible subdivisions ${ }^{16,17}$.

Moreover, the studies quoted took place in countries such as USA, Turkey and Canada. Due to the very nature of adolescence, a stage extremely affected by the environment, the previous studies may not be generalized or applicable to a population of adolescents residing in a South American developing country ${ }^{16}$.

With that in mind, the present study focused on a defined population - adolescents with epilepsy belonging to an age interval based on criteria from the World Health
Organization ${ }^{18}$ in Brazil not yet studied at this present time. In this background, we aimed to assess, using available psychological tools common to our service and different from the ones used in the quoted studies, the scores of anxiety and depression within the described population and compare the results with a control group.

\section{METHOD}

\section{Participants}

The study sample consisted of 101 adolescents assessed in the year 2011-2012. Case participants (50 subjects with epilepsy) attended the pediatric Epilepsy Outpatient Department of the University Hospital (UNICAMP, Campinas, Brazil). Control participants (51 subjects without epilepsy) were selected from public schools in Campinas-SP, Brazil. The inclusion criteria were: age between 10 and 19 years, according to the WHO criteria ${ }^{18}$, elementary and high school education level, ability to answer the questions by himself/ herself, medical diagnosis of epilepsy for more than 2 years (criteria established in service for epilepsy diagnosis) for the group with epilepsy (case group) and no diagnosis of epilepsy for the group without epilepsy (control group). The exclusion criteria for both groups were: if they had had brain surgery, used a concomitant medication with central nervous system effects (except the anticonvulsant used to treat the epilepsy), or had another progressive neurological or psychiatric illness.

Mean years of age of case group was 14.02 (Standard Deviation $(\mathrm{SD})=1.99$ ) and of control group was 12.63 $(\mathrm{SD}=1.62)$; this difference was statistically significant $(\mathrm{p}<0.01)$. The majority of adolescents of the case group were male (68\%), students (96\%), and attending elementary school (72\%). Most adolescents of control group were female (58.82\%), students (100\%), and attending elementary school (90.19\%). The difference of gender was statistically significant $(\mathrm{p}=0.007)$. For specific features of the case group, with respect to medical data, most adolescents had focal seizures (62\%), had frequent seizures (56\%), were on monotherapy (58\%), and mean of onset seizure was 6.4 years; with respect to psychological variables, $84 \%$ of adolescents reported perception of seizure control; and with respect to social aspects, $58 \%$ reported occurrence of seizures in public places.

\section{Measures}

1) Identification card with demographic data (age, sex, education level, and job) for both groups and, for case group only, epilepsy data (age of onset, seizure frequency, type of seizure and drug treatment); all these data was collected by the researcher that used medical records available at the pediatric epilepsy clinic. Regarding frequency of seizures, two groups were considered: frequent seizures (seizures that 
occur within one year) and not frequent seizures (patients without seizures for one year). Type of seizure was classified according to the International League Against Epilepsy classification of epileptic seizures ${ }^{19}$ : focal seizures, generalized seizures, focal + generalized seizures. Drug treatment was classified in monotherapy (one type of medication) and polytherapy (two or more medications). Data on psychological variable were also collected. Perception of seizure control data was obtained through patient reports, in which they evaluated whether their seizures were controlled or not; these data were subjective and may reflect alterations in the intensity and/or frequency of the seizures ${ }^{15}$. Patients were also questioned if they had had occurrence of seizures in public places (yes/no).

2) Beck Depression Inventory $(\mathrm{BDI})^{20}$, validity and reliability have been tested by Cunha ${ }^{21}$. The BDI includes a 21-item self-report was used to measure depression. Each of the items contains a 4-point severity rating scale. The scoring algorithm defines scores of 0-9 points as indicating minimum depression; 10-16 points as indicating low depression; 17-29 points as indicating moderate depression; and 30-63 points as indicating major depression. The BDI is being used as a standard reference and is one of the most common self-report scales used to assess depression ${ }^{22}$ including in adolescents ${ }^{23}$.

3) State-Trait Anxiety Inventory $(\mathrm{STAI})^{10}$ validated in Portuguese language by Biaggio and Natalício ${ }^{24}$. The test is divided in two sections: I - presents 20 statements related to how the person feels most of the time (Trait); II - presents 20 statements related to how the person feels at the time of assessment (State). To assess the level of trait anxiety and/or state, it is necessary to first apply a correction to the scores obtained on each item: the values of items $1,6,7,10,13,16$ and 19 of the Trait scale and 1, 2, 5, 8, 10, 11, 15, 16, 19 and 20 of the State scale must be inverted (in a way that 1 becomes 4, 2 becomes 3, 3 becomes 2 and 4 becomes 1). After that, scores obtained on each item are summed up and classified accordingly, to assess the level of anxiety: low, scores between 20 and 34; moderate, scores between 35 and 49; high, scores between 50 and 64; and very high, between 65 and $80^{25}$. STAI is widely used in monitoring anxiety states ${ }^{26}$ and is also an instrument used to assess anxiety in children and adolescents ${ }^{10}$.

\section{Procedure}

Initially the Ethics Committee of Universidade Estadual de Campinas (UNICAMP) approved the research (number 176/2005). After that, written informed consent was obtained from all subjects and their companions (the one with legal responsibility over the subject), on the day of the outpatient consultation, in an interview to explain the procedures. Subjects were assessed individually at the outpatient clinic of Psychology Applied to Neurology at the
University Hospital of UNICAMP. On this first day, the objective was to create a positive bond between the professional and subject (interview/presentation stage). On the second day, one week later, the objective was to apply the tools of research (the assessment stage). The selection of subjects for the case group obeyed the demand of our neurology outpatient clinic, according to the criteria for inclusion and exclusion, acceptance of the subject and responsibility to take the research.

The selection of subjects of control group was according to the criteria of inclusion and exclusion, acceptance of the subject and responsibility to take the research. Two public schools in Campinas-SP, Brazil, both of elementary and high-school levels, were chosen by lottery. After the headmaster's authorization, the students were taught about the research and those who had an interest in participating took the written informed consent home to get their parents' signed authorization (interview or presentation stage). All the adolescents of control group were assessed at the individual class of their school, when the researcher returned to the school to apply the tools of the research (assessment stage).

\section{Statistics analysis}

To describe the sample profile according to the study variables, data was comprised of: categorical variables with values of percentage (\%), and descriptive statistics (with measurements of position and dispersion - mean, standard deviation, minimum, maximum and median) for continuous variables (scores of scales).

To compare numerical variables between two groups we used the Mann-Whitney test and Analysis of Covariance (ANCOVA) when needed to adjust for age and sex.

The level of significance for statistical test was $5 \%$ $(\mathrm{p}<0.05)$.

\section{RESULTS}

Data on depression (BDI), state anxiety and trait anxiety scores (STAI) from both groups is listed in Table 1.

Regarding symptoms of depression, no statistically significant differences were found between the two groups. On average, the case group was found in the minimum depression sub-category while the control group was found in the low depression sub-category (Table 1).

The absence of statistically significant differences between the two groups was also a finding for anxiety symptoms (Table 1).

Table 2 show correlations between frequency of seizures, perception of seizure control, occurrence of seizure in public places and STAI and BDI.

A statistically significant result was found in the correlation between low trait and state anxiety versus not frequent 
seizures (medical data, $\mathrm{p}=0.012$ and $\mathrm{p}=0.027$, respectively). Similar results were observed for low trait and state anxiety versus perception of seizure control (psychological variable, $p=0.039$ and $p=0.010$, respectively).

A statistically significant result was observed when correlating occurrence of seizures in public places (social aspect) with high depression scores $(p=0.046)$ and trait anxiety ( $\mathrm{p}=0.003)$.

Despite the difference in the mean points, in terms of percentages, the majority of adolescents from both case group $(72 \%)$ and control group (66\%) remained in the minimum depression sub-category of the BDI (Figure 1).

In the trait anxiety component, the majority of adolescents of both case group (56.86\%) and control group $(47.05 \%)$ scored for moderate anxiety. In the state anxiety component, the majority of adolescents from case group scored for low anxiety (48\%), and the majority of adolescents from control group was divided between low and moderate anxiety (43.13\% each) (Figure 2).

\section{DISCUSSION}

In recent decades there has been a great interest in the study of variables that control the impact of epilepsy, variables that go beyond the seizures. It has been noted the importance of psychosocial and psychiatric conditions and their influence in determining the well-being of individuals in a chronic medical condition ${ }^{27}$.

First of all, our study showed that there were no statistically significant differences between the group of adolescents with epilepsy and control group when comparing depression scores and anxiety scores. These new findings are particularly surprising, because epilepsy

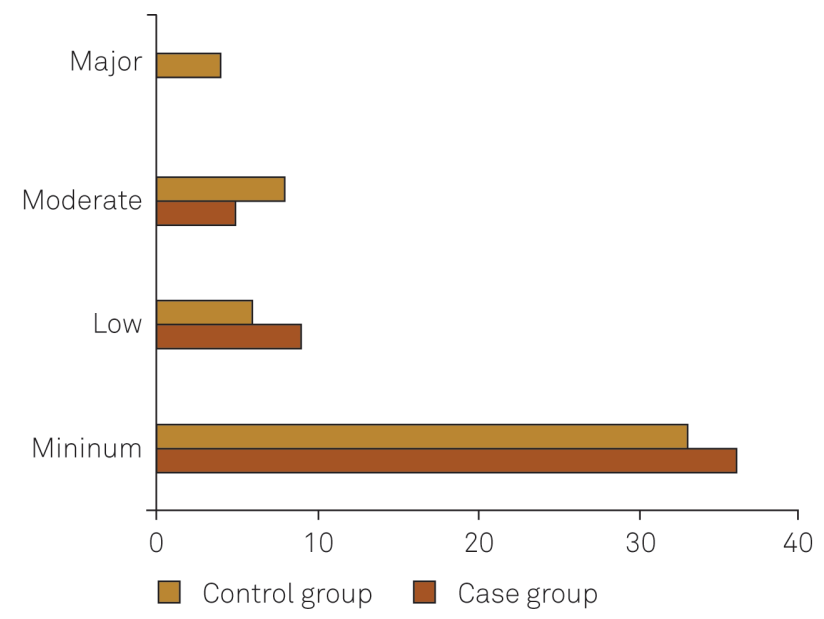

Number of subjects

Figure 1. Depression in case group vs control group. was reported to correlate with high prevalence of depression and anxiety ${ }^{2,3,13}$. One must consider the conditions that make difficult to compare the studies already mentioned $^{15}$. The use of different instruments, different methodologies, characteristics of the population, form of assessment tests, different countries in which the research took place, and sub-categories analyzed may be factors of variability.

In the demographic analysis of the groups, a statistically significant difference was found; the subjects of case group presented a mean age higher than the subjects in the control group. Associated to this piece of information, we recall that we found no statistically significant difference between the scores of depression and anxiety for both groups even after adjusting for age and sex. Considering the data altogether, this higher age for case group may be related to a more mature development state and to more access to mental health treatment, as described by Ott et al. ${ }^{11}$ from his study, it was found that children of older age were more likely to have received mental health treatment. The access to treatment may be related to a better knowledge of the disease and, therefore, associated with better coping with the epilepsy - leading to scores no different from the ones of the control group.

In a chronic disease like epilepsy, the subject may be controlled by different physical, psychological and social variables, contingencies that are linked to the manner with which individuals perceive themselves and perceive their relationship with the environment.

When our present results (scores of anxiety/depression) were analyzed against the disease variables (medical, psychological and social), meaningful correlations were observed. Concerning frequency of seizures (medical data), the correlations showed positive results between low frequency of

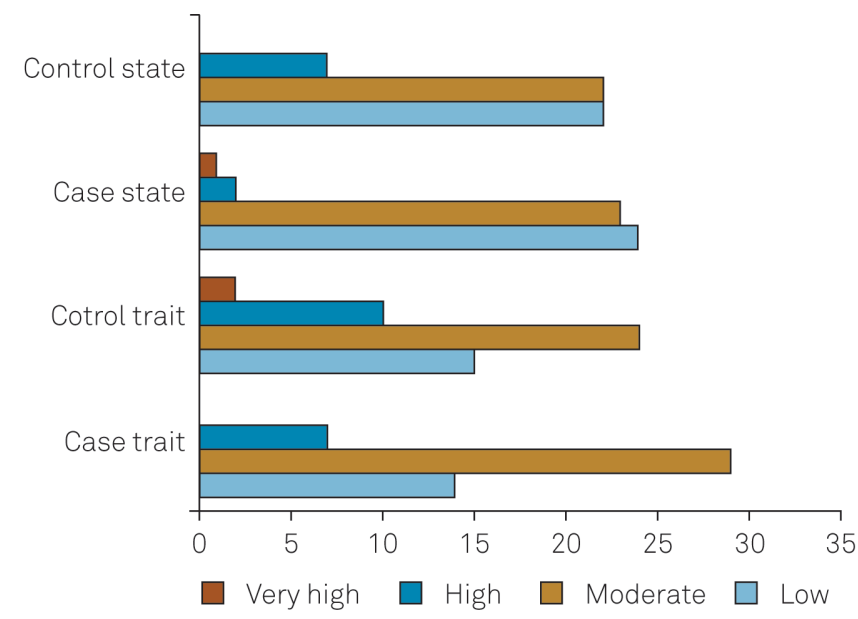

Number of subjects

Figure 2. Anxiety in case group (state and trait domains) vs control group (state and trait domains). 
Table 1. Results of Depression, Anxiety State and Anxiety Trait in case group and control group.

\begin{tabular}{|c|c|c|c|c|c|c|c|}
\hline Dimensions & Mean & SD & Minimum & Median & Maximum & p-value* & $p$-value** \\
\hline \multicolumn{8}{|l|}{ Depression } \\
\hline Case group & 6.30 & 6.20 & 0 & 4 & 19 & 0.321 & 0.316 \\
\hline Control group & 10.10 & 11.40 & 0 & 6 & 52 & & \\
\hline \multicolumn{8}{|l|}{ State anxiety } \\
\hline Case group & 36.20 & 8.90 & 20 & 35 & 67 & 0.529 & 0.267 \\
\hline Control group & 37.50 & 9.40 & 23 & 36 & 60 & & \\
\hline \multicolumn{8}{|l|}{ Trait anxiety } \\
\hline Case group & 40.00 & 8.80 & 23 & 39.5 & 60 & 0.886 & 0.881 \\
\hline Control group & 40.50 & 10.50 & 26 & 39 & 65 & & \\
\hline
\end{tabular}

SD: Standard deviation. * $\mathrm{p}$-value referring to the test of Mann-Whitney to compare variables between groups (case group vs control group); $* * \mathrm{p}$-value referring to the ANCOVA - covariates: age, sex.

seizures and low scores of trait and state anxiety. Perception of seizure control (psychological variable) was positively correlated to low scores of trait and state anxiety. With regards to occurrence of seizures in public places (social aspect), the correlations showed positive results between high scores of depression and trait anxiety and occurrence of seizures in public places.
We could notice the conjugated influence of medical, psychological and social variables in controlling the studied adolescents' responses. Such influence guides us to the importance of the bio-psycho-social aspects for a better comprehension of the human being in its totality.

Of all the factors that may influence the results we believe that, from the psychological perspective, the development

Table 2. Correlations between frequency of seizures, perception of seizure control, occurence of seizure in public places and STAl and BDI.

\begin{tabular}{|c|c|c|c|c|c|c|c|}
\hline & $\mathrm{N}$ & Mean & SD & Minimum & Median & Maximum & $p$-value* \\
\hline \multicolumn{8}{|c|}{ Frequency of seizures } \\
\hline \multicolumn{8}{|c|}{ STAI - Trait anxiety } \\
\hline Frequent & 28 & 42.64 & 8.06 & 27.00 & 41.50 & 57.00 & \\
\hline Not frequent & 22 & 36.59 & 8.65 & 23.00 & 37.00 & 60.00 & 0.012 \\
\hline \multicolumn{8}{|c|}{ STAI - State anxiety } \\
\hline Frequent & 28 & 38.46 & 8.91 & 23.00 & 36.50 & 67.00 & \\
\hline Not frequent & 22 & 33.32 & 8.14 & 20.00 & 32.50 & 51.00 & 0.027 \\
\hline \multicolumn{8}{|l|}{$\mathrm{BDI}$} \\
\hline Frequent & 28 & 7.32 & 6.32 & 0.00 & 6.50 & 29.00 & \\
\hline Not frequent & 22 & 5.05 & 5.91 & 0.00 & 3.00 & 21.00 & 0.116 \\
\hline \multicolumn{8}{|c|}{ Perception of seizure control } \\
\hline \multicolumn{8}{|c|}{ STAI - Trait anxiety } \\
\hline Controlled & 42 & 38.93 & 8.52 & 23.00 & 38.00 & 60.00 & \\
\hline Not controlled & 08 & 45.50 & 8.51 & 29.00 & 47.00 & 57.00 & 0.039 \\
\hline \multicolumn{8}{|c|}{ STAI - State anxiety } \\
\hline Controlled & 42 & 34.55 & 7.32 & 20.00 & 33.50 & 51.00 & \\
\hline Not controlled & 08 & 44.88 & 11.65 & 32.00 & 41.50 & 67.00 & 0.010 \\
\hline \multicolumn{8}{|l|}{ BDI } \\
\hline Controlled & 42 & 5.50 & 5.07 & 0.00 & 3.00 & 21.00 & \\
\hline Not controlled & 08 & 10.63 & 9.60 & 0.00 & 9.00 & 29.00 & 0.221 \\
\hline \multicolumn{8}{|c|}{ Occurrence of seizures in public places } \\
\hline \multicolumn{8}{|c|}{ STAI - Trait anxiety } \\
\hline Yes & 29 & 42.93 & 8.61 & 25.00 & 42.00 & 60.00 & \\
\hline No & 21 & 35.90 & 7.42 & 23.00 & 36.00 & 51.00 & 0.003 \\
\hline \multicolumn{8}{|c|}{ STAI - State anxiety } \\
\hline Yes & 29 & 38.17 & 9.72 & 23.00 & 37.00 & 67.00 & \\
\hline No & 21 & 33.48 & 6.89 & 20.00 & 33.00 & 51.00 & 0.057 \\
\hline \multicolumn{8}{|l|}{$\mathrm{BDI}$} \\
\hline Yes & 42 & 7.86 & 7.02 & 0.00 & 6.00 & 29.00 & \\
\hline No & 08 & 4.19 & 4.07 & 0.00 & 3.00 & 13.00 & 0.046 \\
\hline
\end{tabular}

SD: Standard deviation; STAI: State-Trait Anxiety; BDI: Beck Depression Inventory. ${ }^{\star} p$-value referring to the test of Mann-Whitney to compare variables. 
phases influence deserves to be discussed. Adolescence is a life stage characterized by intense emotional and physical transformation, and is determined by culture. These young people are overwhelmed by intense feelings while going through significant changes and assuming new behaviors ${ }^{29}$. These significant changes may come laden with feelings of inadequacy, insecurity, loss of control, and fear of the unknown, all of which can lead to the emergence of heightened anxiety experiences. Since the majority of adolescents in both groups had moderate scores of anxiety trait, we can assume that this trait is inherent to the stage itself - adolescence -, regardless of the disease - epilepsy.

Epilepsy patients have the perception of their illness through their seizures. Souza and Salgado ${ }^{15}$ draw attention to the perception of seizure control as an important factor in the control of the disease, even if, from the medical perspective, the disease is not considered controlled. Patient may have frequent seizures, but these decreased in the current period as he may deem it under control. According to the authors, the positive perception of seizure control seems to be an important factor to mitigate the impact of potentially stressful experiences. The correlations between positive perception of seizure control and low scores of anxiety found in our results seem to support the influence of the psychological aspects that control the well-being in this sample of adolescents.
These results are corroborated by recent studies with this same population. Siqueira et al. ${ }^{27}$ investigated aspects that show that these adolescents have good knowledge of epilepsy, good social support perception, perception of seizure control and no significant differences when compared with a control group in rates of self esteem. Cancian ${ }^{30}$ observed that the same adolescents with epilepsy seem to have better coping with the disease. In this sense, it is possible to infer that, in the status of a well-managed disease, epilepsy may not be of great influence in the development of depression and anxiety.

Our study had limitations. The sample was relatively small, and restricted to one research center and country; there was no randomization due to selection difficulties and dropouts. Even though following the WHO criteria for the classification of adolescence, the age range still showed to be too large for the analysis of the results.

When considering the medical and psychosocial factors of development, we suggest that future studies in this area focus on analysis of age subcategories within the age range previously established for adolescence, increased number of subjects, different assessment tools and different settings for must prove valuable in designing comprehensive and effective interventions to promote better social outcomes in adolescence bearing this illness.

\section{References}

1. Mitchell WG, Scheier LM, Baker SA. Psychosocial, behavioral, and medical outcomes in children with epilepsy: a developmental risk factor model using longitudinal data. Pediatrics. 1994;94(4):471-7.

2. Valente KDR, Souza ST, Kuczynski, Negrão N. Depressão em crianças e adolescentes com epilepsia. Rev Psiq Clín. 2004;31(6):290-9.

3. Hankin BL. Adolescent depression: description, causes, and interventions. Epilepsy Behav. 2006;8(1):102-14. http://dx.doi.org/10.1016/ j.yebeh.2005.10.012

4. Jacoby A, Baker GA, Steen N, Potts P, Chadwick DW. The clinical course of epilepsy and its psychosocial correlates: findings from a $U$. K. Community study. Epilepsia. 1996;37(2):148-61. http://dx.doi.org/ 10.1111/j.1528-1157.1996.tb00006.x

5. Ettinger AB, Weisbrot DM, Nolan EE, Gadow KD, Vitale SA, Andriola MR et al. Symptoms of depression and anxiety in pediatric epilepsy patients. Epilepsia. 1998;39(6):595-9. http://dx.doi.org/10.1111/j.15281157.1998.tb01427.x

6. Reynolds CR, Richmond BO. Revised Children's Martijest Anxiety Scale (RCMAS). Los Angeles: Western Psychological Services; 1985.

7. Kovacs M. The Children's Depression Inventory (CDI). North Tonawanda: Multi-Health Systems; 1992.

8. Dunn DW, Austin JK, Huster GA. Symptoms of depression in adolescents with epilepsy. J Am Acad Child Adolesc Psychiatry. 1999;38(9):1132-8. http://dx.doi.org/10.1097/00004583-19990900000017

9. Oguz A, Kurul S, Dirik E. Relationship of epilepsy-related factors to anxiety and depression scores in epileptic children. J Child Neurol. 2002;17(1):37-40. http://dx.doi.org/10.1177/088307380201700109

10. Spielberger CD, Gorsuch RL, Lushene RE. Manual for State-Trait Anxiety Inventory. Palo Alto: Consulting Psychologists; 1970.
11. Ott D, Siddarth P, Gurbani S, Koh S, Tournay A, Shields WD et al. Behavioral disorders in pediatric epilepsy: unmet psychiatric need. Epilepsia. 2003;44(4):591-7. http://dx.doi.org/10.1046/j.1528-1157.2003. 25002.x

12. Caplan R, Siddarth P, Gurbani S, Hanson R, Sankar R, Shields WD. Depression and anxiety disorders in pediatric epilepsy. Epilepsia. 2005;46(5):720-30. http://dx.doi.org/10.1111/j.1528-1167.2005.43604. $x$

13. Loney JC, Wirrell EC, Sherman EMS, Hamiwka LD. Anxiety and depressive symptoms in children presenting with a first seizure. Pediatr Neurol. 2008;39(4):236-40. http://dx.doi.org/10.1016/ j.pediatrneurol.2008.07.005

14. Ekinci O, Titus JB, Rodopman AA, Berkem M, Trevathan E. Depression and anxiety in children and adolescents with epilepsy: prevalence, risk factors, and treatment. Epilepsy Behav. 2009;14(1):8-18. http:// dx.doi.org/10.1016/j.yebeh.2008.08.015

15. Souza EAP, Salgado PCB. A psychosocial view of anxiety and depression in epilepsy. Epilepsy Behav. 2006;8(1):232-8. http://dx. doi.org/10.1016/j.yebeh.2005.10.011

16. United Nations Children's Fund - UNICEF. adolescent development: perspectives and frameworks - a discussion paper. New York: United Nations Children's Fund; 2006.

17. Sacks D, Canadian Paediatric Society. Age limits and adolescents. Paediatr Child Health. 2003;8(9):577-8.

18. Organización Mundial de la Salud. Programación para la salud y el desarrollo de los adolescentes: informe de un grupo de estúdio OMS/FNAUAP/UNICEF sobre Programación para la salud de los. Ginebra: Organización Mundial de la Salud; 1996. (Serie de informes técnicos, 886) 
19. Commission on Classification and Terminology of the International League Against Epilepsy. Proposal for revised clinical and electroencephalographic classification of epileptic seizures. Epilepsia. 1981;22(4):489-501. http://dx.doi.org/10.1111/j.1528-1157.1981.tb06159.x

20. Beck AT, Ward CH, Mendelson M, Mock JU, Erbaugh J. An inventory for measuring depression. Arch Gen Psychiatry. 1961;4(6):561-71. http://dx.doi.org/10.1001/archpsyc.1961.01710120031004

21. Cunha J. Escalas Beck. São Paulo: Casa do Psicólogo; 2001.

22. Del Porto JÁ. Aspectos gerais das escalas para avaliação de depressão. In Centro de Pesquisa em Psicobiologia Clínica do Departamento de Psicobiologia da Escola Paulista de Medicina. Escalas de avaliação para monitorizarão de tratamento com psicofármacos. 93-100. São Paulo: Escola Paulista de Medicina; 1989.

23. Benett DS, Ambrosini PJ, Bianchi M, Barnett D, Metz C, Rabinovich H. Relationship of Beck Depression Inventory factors to depression among adolescents. J Affect Disord.1997;45(3):127-34. http://dx.doi. org/10.1016/S0165-0327(97)00045-1

24. Biaggio AMB, Natalício. Manual para o Inventário de Ansiedade Traço Estado (IDATE). Rio de Janeiro: Centro Editor de Psicologia Aplicada; 1979.
25. Salles LF, Silva MJP. Effect of flower essences in anxious individuals. Acta Paul Enferm. 2012;25(2):238-42. http://dx.doi.org/10.1590/ S0103-21002012000200013

26. Fankhauser MP, German ML. Understanding the use of behavioral rating scales in studies evaluating the efficacy of antianxiety and antidepressant drugs. Am J Hosp Pharm. 1987;44(9):2087-100.

27. Siqueira NF, Guerreiro MM, Souza EAP. Self-esteem, social support perception and seizure controllability perception in adolescents with epilepsy. Arq Neuropsiquiatr. 2011;69(5):770-4. http://dx.doi.org/ 10.1590/S0004-282X2011000600009

28. Oliveira JCS, Sisto FF. Construção de uma escala de ansiedade para pacientes de ambulatório: um estudo exploratório. Psicol Teoria Prática. 2004;6(1):45-57.

29. Polanczyk GV, Denardin D, Laufer T, Pianca T, Rohde LA. O transtorno de déficit de atenção/hiperatividade na adolescência. Adolesc Latinoam. 2002;3(2):1-23.

30. Cancian F. Significação e enfrentamento de adolescentes portadores de epilepsia [dissertação]. Campinas: Universidade Estadual de Campinas; 2011. 